\title{
Acalculous Acute Pancreatitis in a COVID-19 Patient
}

\author{
Pedro Antunes Meireles $^{1,2}$, Filipe Bessa ${ }^{1}$, Pedro Gaspar ${ }^{1,3}$, Inês Parreira ${ }^{1}$, Virgílio Dias Silva ${ }^{1,4}$, Catarina Mota ${ }^{1,3}$ Lourdes Alvoeiro $^{1}$ \\ ${ }^{1}$ Serviço de Medicina 2, Hospital de Santa Maria, Centro Hospitalar Universitário Lisboa Norte, Lisbon, Portugal \\ ${ }^{2}$ Serviço de Oncologia Médica, Instituto Português de Oncologia de Lisboa Francisco Gentil, Lisbon, Portugal \\ ${ }^{3}$ Faculdade de Medicina da Universidade de Lisboa, Lisbon, Portugal \\ ${ }^{4}$ Serviço de Medicina Intensiva, Hospital de Santa Maria, Centro Hospitalar Universitário Lisboa Norte, Lisbon, Portugal
}

Received: 08/05/2020

Accepted: $12 / 05 / 2020$

Published: $13 / 05 / 2020$

How to cite this article: Antunes Meireles P, Bessa F, Gaspar P, Parreira I, Dias Silva V, Mota C, Alvoeiro L. Acalculous acute pancreatitis in a COVID-19 patient. EJCRIM 2020;7: doi:10.12890/2020_001710.

Conflicts of Interests: The Authors declare that there are no competing interests.

This article is licensed under a Commons Attribution Non-Commercial 4.0 License

\section{ABSTRACT}

Coronavirus disease 2019 (COVID-19) is a multisystemic condition caused by severe acute respiratory syndrome coronavirus 2 (SARSCoV-2) with manifestations ranging from mild upper respiratory symptoms to cytokine storm causing acute respiratory distress syndrome. Pancreatic exocrine tissue and endocrine islets both express angiotensin-converting enzyme 2 (ACE2), the proven receptor for SARSCoV-2 cell internalization. An increase in pancreatic enzymes has been increasingly recognized in patients with COVID-19, but little is known about the real prevalence of acute pancreatitis in this population. We report a case of acute acalculous pancreatitis in a COVID-19 patient.

\section{LEARNING POINTS}

- Acute pancreatitis may be a manifestation of SARS-CoV-2 infection.

- Future studies must address the real impact of pancreatic involvement in COVID-19 patients.

\section{KEYWORDS}

SARS-CoV-2, amylase, lipase, acute pancreatitis

\section{CASE DESCRIPTION}

A 36-year-old black woman was admitted to our ward with a diagnosis of SARS-CoV-2 pneumonia after a 4-day history of dry cough, breathlessness and fever. Her medical history included post-HELLP syndrome stage $V$ chronic kidney disease and arterial hypertension, treated with nifedipine and carvedilol. On physical examination, she had bilateral crackles without other relevant clinical features. Blood analysis revealed lymphopenia and increased levels of lactate dehydrogenase, ferritin, C-reactive protein (11.9 mg/dl) and procalcitonin (5.61 ng/l). A chest CT scan showed bilateral ground-glass opacities with $75-100 \%$ lung involvement. The patient started supplemental oxygen therapy.

During the first week, she had remarkable clinical, laboratory and radiological improvement, with no need for additional oxygen therapy. However, on the 7th day of admission (11th day of disease), she developed nausea, vomiting and a belt-like epigastric pain, with no fever or other physical findings. Laboratory tests showed a 10-fold elevation in amylase and lipase levels (718 U/I and 631 U/I, respectively) which increased the following day. Abdominal ultrasound showed no signs of cholelithiasis and an angio-abdominal CT scan excluded ischaemic changes. The results of further evaluation are shown in Table 1. 


\begin{tabular}{|l|l|}
\hline Total cholesterol (mg/dl) & 119 \\
\hline Triglycerides (mg/dl) & 120 \\
\hline Calcium (mg/dl) & 8.6 \\
\hline ANA screening & Negative \\
\hline Anti-HIV 1 and 2 & Negative \\
\hline HBV & \\
\hline HBs antigen & Negative \\
\hline Anti-HBs antibody & Positive \\
\hline Anti-HBc antibody & Positive \\
\hline Anti-HCV antibody & Negative \\
\hline Anti-Coxsackie antibody (lgM/lgG) & Negative/Negative \\
\hline Anti-herpes virus 1 antibody (lgM/lgG) & Negative/Negative \\
\hline Anti-herpes virus 2 antibody (lgM/lgG) & Negative/Negative \\
\hline Anti-CMV antibody (lgM/lgG) & Negative/Positive \\
\hline
\end{tabular}

Table 1. Laboratory investigations

ANA, antinuclear antibodies; $C M V$, cytomegalovirus; $H B V$, hepatitis B virus; $H C V$, hepatitis $C$ virus; HIV, human immunodeficiency virus.

Given the typical abdominal pain and the presence of increased levels of pancreatic enzymes, we assumed the diagnosis of acute pancreatitis. The patient recovered clinically under supportive care only and laboratory tests improved. An abdominal CT scan on the 3rd day of disease showed no pancreatic abnormalities.

\section{DISCUSSION}

Although viral acute pancreatitis has been described in other viral infections, pancreatic involvement in SARS-CoV-2 infection is still poorly defined. We report a case of acute pancreatitis in a patient with SARS-CoV-2 infection. Other causes of acalculous acute pancreatitis were excluded, namely alcohol and drug consumption, trauma, hypertriglyceridemia, hypercalcemia, autoimmunity and other infectious causes. No major morphological abnormality was found on the abdominal CT scan and no steroid therapy was given during hospitalization.

Liu et al $^{[1]}$ showed an increase in amylase and lipase in a series of 121 patients admitted with COVID-19 pneumonia, suggesting some degree of pancreatic injury in these patients. However, no information about the clinical picture was given since patients were stratified based on the severity of respiratory disease.

Our patient developed symptoms of pancreatitis during resolution of her lung infection, associated with a more than 10-fold increase in serum amylase and lipase, which contrasts with previous reported cases where patients had no more than a 3-fold increase in pancreatic enzymes ${ }^{[2]}$. Similarly, Anand et al ${ }^{[3]}$ have reported the case of a 59-year-old female patient who was diagnosed with acute pancreatitis based on typical abdominal pain and imaging findings 10 days after positive PCR-confirmed SARS-CoV-2 infection.

Given the temporal dissociation between pancreatitis and the rest of the clinical picture, we suggest that pancreatic involvement likely arises from an immune-mediated inflammatory response rather than a direct viral lesion, even though ACE2 is highly expressed in pancreatic tissue $^{[4]}$. 


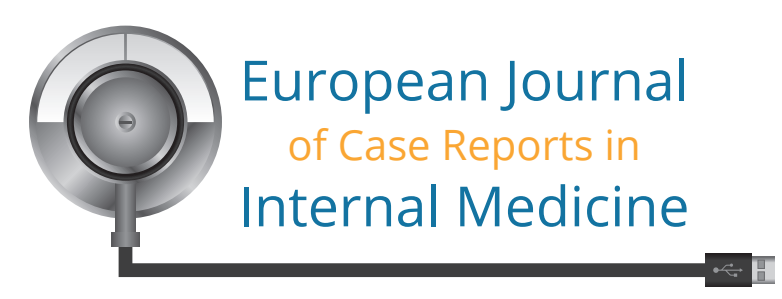

The authors report a case of acute pancreatitis in a COVID-19 patient, highlighting the importance of considering SARS-CoV-2 as a new aetiological agent of acute viral pancreatitis. Further studies are needed to establish the real prevalence and clinical significance of pancreatic injury in COVID-19 patients. We suggest that pancreatic enzymes should be evaluated in COVID-19 in-patients presenting with gastrointestinal symptoms, since it could reveal unrecognized pancreatic involvement in this population.

\section{REFERENCES}

1. Liu F, Long X, Zou W, Fang M, Wu W, Li W, et al. ACE2 expression in pancreas may cause pancreas damage after SARS-CoV-2 infection. Clin Gastroenterol Hepatol 2020 Apr 2. pii: S1542-3565(20)30537-1. doi: 10.1016/j.cgh.2020.04.040 [Epub ahead of print]. Available from: https://www.medrxiv.org/content/10.1101/2020.02.28.20029181v1.

2. Wang F, Wang H, Fan J, Zhang Y, Wang H, Zhao Q. Pancreatic injury patterns in patients with COVID-19 pneumonia. Gastroenterology 2020 Apr 1. pii: S0016-5085(20)304091. doi: 10.1053 /j.gastro.2020.03.055 [Epub ahead of print].

3. Anand ER, Major C, Pickering O, Nelson M. Acute pancreatitis in a COVID-19 patient [Letter to the Editor]. Br J Surg 2020 Apr 27. doi: 10.1002/bjs.11657 [Epub ahead of print].

4. Yang JK, Lin SS, Ji XJ, Guo LM. Binding of SARS coronavirus to its receptor damages islets and causes acute diabetes. Acta Diabetol 2010:47:193-199. 